\title{
Çocuk Acil Servise Düşmeye Bağlı Travma Nedeniyle Getirilen Olgular
}

\author{
Cases Admitted to Pediatric Emergency Department Due to Trauma Related to \\ Fall
}

\author{
๑llknur Fidancı' ${ }^{1}, \odot$ Okşan Derinöz Güleryüz ${ }^{2}$, $\odot$ Aslıhan Tokgöz ${ }^{3}$
}

\begin{abstract}
'Sağlık Bilimleri Üniversitesi, Ankara Eğitim ve Araştırma Hastanesi, Çocuk Acil Kliniği, Ankara, Türkiye
${ }^{2}$ Gazi Üniversitesi Tıp Fakültesi, Çocuk Sağlığı ve Hastalıkları Ana Bilim Dalı, Çocuk Acil Bilim Dalı, Ankara, Türkiye

${ }^{3}$ Gazi Üniversitesi Tıp Fakültesi, Çocuk Sağlığı ve Hastalıkları Ana Bilim Dalı, Ankara, Türkiye
\end{abstract}

\section{ÖZ}

Amaç: Çocuk acil ünitemize düşme nedeniyle başvuran travma olgularının kaza mekanizmasını ve kaza ilişkili ortaya çıkan sakatlıkları değerlendirmeyi amaçladık.

Gereç ve Yöntem: Çalışma 01.06.2009 - 01.02.2010 tarihleri arasında Gazi Üniversitesi Tıp Fakültesi Çocuk Acil Servis' in de ileriye dönük olarak düşmeye bağlı travma nedeniyle başvuran hastaların tanı, tedavi ve takipleri değerlendirilerek yapılmıştır.

Bulgular: Çalışmaya, 126 (\%60)'sı erkek 210 olgu dahil edildi. Yaş ortalaması 44,5 $\pm 45,01$ (minumum:1 ay; maksimum:17 yıl) aydı. Yüz elli yedi hasta (\%75), beş yaşın altında idi. $149(\% 73,4)^{\prime}$ unun ev içinde düştüğü, ev içinde düşen olguların $91(\% 44,2)$ 'inin $90 \mathrm{~cm}$ altı; 16 $(\% 7,6)$ 'sının 90 cm üzeri yükseklikten düştüğü görüldü. En çok zedelenen vücut bölgesi değerlendirildiğinde, $142(\% 72,4)$ olgunun baş-boyun bölgesinden yaralandığı görüldü. Bu olgularında $76(\% 38,8)$ 'sın da yumuşak doku travması, $36(\% 18,4)$ 'sında laserasyon-kesi mevcuttu. $141(\% 67,1)$ olguya direkt grafi, 53 (\%25.2) hastaya kraniyal bilgisayarl tomografi çekildiği görüldü. Yetmiş beş hasta (\%40.1) mevcut klinik durumu nedeniyle acil gözlem ünitesine izleme alınmıştı. Bu olguların 54 (\%72)'ü kafa travması olan olgulardı. Olguların 30 (\%16)'una baş ve yüz bölgesindeki kesi-laserayon nedeniyle sütür atılmıştı. Değerlendirilen tüm hastalar herhangi bir mortalite ve morbidite olmadan muayene, tedavi ve/veya gözlem ardından taburcu edildi.

Sonuç: Düşme ilişkili travmalar sıklıkla ev içinde meydana gelmektedir ve en sık baş boyun bölgesi yaralanmaları görülmektedir. Özellikle okul öncesi dönemde yaşam ve oyun alanları evler olan çocukların sağlıklı şartlarda büyüyebilmesi ve düşme ilişkili travmalar nedeniyle acil servis başvurularının önlenmesinde ailelere çok iş düşmektedir. Güvenli ev ortamının nasıl oluşturulacağı ve alınacak önlemler hekimler tarafından ailelere anlatılmalıdır.

Anahtar Kelimeler: Düşme, çocuk acil, kafa travması

\section{ABSTRACT}

Objective: We aimed to evaluate the accident mechanism and related disabilities and trauma cases who presented due to falls in the pediatric emergency service.

Material and Method: The study was conducted with a prospective method between 01.06.2009 - 01.02.2010 in Gazi University Medical Faculty Pediatric Emergency Service.

Results: A total of 210 cases, 126 (60\%) of whom were men, were included in the study. The average age was $44.5 \pm 45.01$ (minimum: 1 month; maximum: 17 years) months. One hundred and fifty-seven patients (75\%) were under the age of five. 149 (73.4\%) of them fell inside the house; $90 \mathrm{~cm}$ below 91 (44.2\%) of the cases falling inside the house; It was observed that 16 (7.6\%) fell from a height above $90 \mathrm{~cm}$. When the most injured body area was evaluated, it was seen that 142 (72.4\%) patients had head-neck injuries. Of these cases, 76 (38.8\%) had soft tissue trauma, $36(18.4 \%)$ had laceration-incision. It was observed that direct radiography was performed in 141 (67.1\%) patients, and cranial computed tomography was performed in 53 (25.2\%) patients. Seventyfive patients (40.1\%) were followed up in the emergency observation unit due to their current clinical condition. $54(72 \%)$ of these cases were cases with head trauma. Sutures were performed in 30 (16\%) of the cases due to the incision-laceration on the head and face. All evaluated patients were discharged after examination, treatment and / or observation without any mortality or morbidity.

Conclusion: Traumas caused by falls often occur at home. And the most common injuries are seen in the head and neck region. Families have many duties in preventing emergency room admissions due to fallrelated traumas and children, whose living and playgrounds are houses, especially in the preschool period. Physicians should explain to families how to create a safe home environment and the measures to be taken.

Keywords: Fall, child emergency, head trauma 


\section{GIRIŞ}

Düşmeler, en fazla tıbbi bakım ve hastanede kalmayı gerektiren ölümcül olmayan travma tipidir. Tüm yaşlarda travmaya bağlı hastaneye yatışların ikinci önde gelen nedenidir (1). Travma başvurularının yaklaşık \%30' unu ve tüm Acil Servis ziyaretlerinin \%15' ini oluşturur (2). Düşmelerin çoğu önemli bir yaralanmaya yol açmasada, kafa travmasına yol açan düşmeler halen önemli bir morbidite ve mortalite nedenidir (3).

Düşmelerin neden olduğu yaralanmaların yeri ve mekanizması çocuğun yaşına göre değişir. Mortalite ve morbiditeyi etkileyen nedenler arasında yaş, düşme şekli, düştüğü zeminin yapısı, düşme pozisyonu ve düştüğü yüksekliği önemlidir (4).

Beş yaşından küçük çocuklar düşmeye bağlı yaralanmalara maruz kalma konusunda en büyük risk altındadır. Merak, motor becerilerinin olgunlaşmamış olması ve muhakeme eksikliğinin birleşimi, okul öncesi çocukları düşmeye yatkın hale getirir (5).

$\mathrm{Bu}$ çalışmada acil servise düşmeye bağlı travma nedeniyle başvuran olguların kaza mekanizmasını ve kaza ilişkili ortaya çıkan sakatlıklarının değerlendirilmesi amaçlanmıştır.

\section{GEREÇ VE YÖNTEM}

Çalışma etik onay alındıktan sonra (Tarih 15.6.2009, Karar no:354), 01.06.2009 - 01.02.2010 tarihleri arasında Gazi Üniversitesi Tıp Fakültesi Çocuk Acil Servis'te ileriye dönük olarak yapılmıştır. Çalışma dönemi içinde düşme yakınması ile getirilen 0-18 yaş arasındaki çocuklar acil servisteki ilk müdahaleleri yapıldıktan, aile onamı alındıktan sonra düşmeye neden olan mekanizmayı ve ortaya çıkan sakatlıkları belirlemek amacıyla çalışma veri formuna kaydedilmiştir. Form olgulara ait demografik, düşmenin mekanizmasına ait verileri, hastanın klinik bulgularına ait laboratuvar ve tedavi bulgularını, anne babanın eğitim, sosyoekonomik düzeylerini belirleyen soruları içermektedir.

Çalışmaya gönüllü olur formu imzalanmayan hastalar ile tedavi ve izlem sürecinde hastaneyi izinsiz terk edenler dahil edilmedi.

Ayrıca, yatak, mama sandalyesi, araba koltuğu gibi emniyet kemeri veya yatak korkuluğu/kenarlığı olan yerlerden düşen çocukların ailelerine düşme esnasında gerekli önlemlerin alınıp alınmadığı da sorulmuştur.

Yüksek enerjili travma: "Pediatric Emergency Care Applied Research Network" (PECARN)'a göre 2 yaş altında $90 \mathrm{~cm}, 2$ yaş üstünde $150 \mathrm{~cm}$ üzeri olarak tanımlanmıştır (6).

\section{İstatistik}

Veriler IBM SPSS V23 ile analiz edildi. Kategorik verilerin karşılaştırılmasında kikare testi ve Oneway Anova testi kullanıldı. Yaşların karşılaştırılmasında ise t testi kullanıldı. Analiz sonuçları kategorik veriler için frekans (yüzde) sayısal veriler için ortalama ve standart sapma olarak sunuldu. Önem düzeyi $p<0.05$ olarak alındı.

\section{BULGULAR}

Çalışmaya, düşmeye bağlı travma ile Çocuk Acil servise başvuran 210 olgu dahil edildi, bunların 126 (\%60)'sı erkekti. Yaş ortalaması 44,5 445,01 (en düşük:1 ay; en yüksek:17 yıl) aydı. Yüz elli yedi hasta (\%75), beş yaşın altında idi. Hastaların 130 (\%65)'u yaz aylarında acil servise başvurmuştu. Yetmiş hasta (\%35) ise sonbahar ve kış aylarında acil servise getirilmişti. Doksan dört ( $n=157$; $\% 60)$ olgu 18:00-08:00; 63 ( $n=157 ; \% 40)$ olgu 08:0018:00 saatleri arasında acil servise başvurmuştu.

Düşme olguları ev içi ve dışı düşmeler diye ayrıldığında, $149(\% 73,4)^{\prime}$ unun ev içinde düştüğü, ev içinde düşen olguların 91 (\%44,2)'inin $90 \mathrm{~cm}$ altı; 16 (\%7,6)'sının 90 cm üzeri yükseklikten düştüğü görüldü (Grafik 1 ve Tablo 1). Yaş gruplarına göre değerlendirildiğinde 5 yaş ve altı 127 (\%80) olgunun ev içinde düştüğü; 5 yaş üzeri olguların ise ev dışında düşme ilişkili yaralanma ile acil servise getirildiği görüldü.

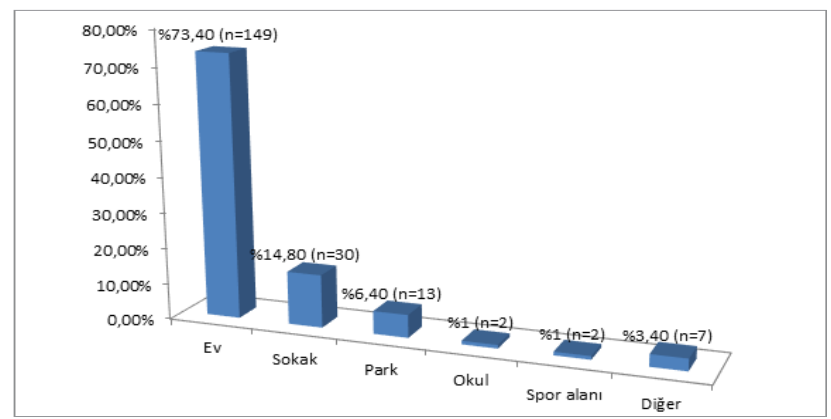

Grafik 1. Düşme ilişkili travmanın meydana geldiği yer

Tablo 1. Olguların düştükleri yerlere göre dağılımı

\begin{tabular}{lc} 
Düşme özelliği & $\mathbf{n}(\%)$ \\
\hline $\mathbf{9 0} \mathbf{c m >}$ & $190(92,4)$ \\
Kendi yüksekliği & $65(31,6)$ \\
Yatak & $26(12,6)$ \\
Beşik & $9(4,4)$ \\
Sandalye/koltuk & $24(11,7)$ \\
Bisiklet & $6(2,9)$ \\
Diğer & $60(29,1)$ \\
Yüksekten düşme, 90 cm< & $16(7,6)$ \\
Ağaç & $2(1)$ \\
Balkon & $5(2,4)$ \\
Kaydıraktan düşme & $5(2,4)$ \\
Ranza & $4(1,9)$ \\
TOPLAM & $206(100)$ \\
\hline
\end{tabular}


Düşme zemini sorulduğunda ev içinde düşen 70 $(\% 48,6)$ olgunun halı zemine; ev dışında düşen 40 (\%64.5) olgunun beton zemine düştüklerini beyan edilmişti. Düşme sırasında ne yaptıkları sorulduğunda ise $95(\% 46,3)$ olgunun oyun oynarken düştüğü; düşme esnasında $35(\% 16,7)$ olgunun bir mobilyaya/eşyaya çarptığı da ifade edilmişti.

En çok zedelenen vücut bölgesi değerlendirildiğinde, $142(\% 72,4)$ olgunun baş-boyun bölgesinden yaralandığı görüldü (Tablo 2). Bu olgularında $76(\% 38,8)$ 'sın da yumuşak doku travması, 36 (\%18,4)'sında laserasyonkesi mevcuttu. $20(\% 9,5)$ hastada laserasyon-kesi baş-yüz bölgesindeydi (Tablo 3). Balkondan düşen hastaların tamamında baş boyun bölgesinde yaralanma mevcuttu (Tablo 4).

\begin{tabular}{lc}
\hline \multicolumn{2}{|c|}{ Tablo 2. Olguların düşme sonrası zedelenen vücut bölgeleri } \\
\hline Vücut bölgesi & $\mathbf{n}(\%)$ \\
\hline Baş-yüz bölgesi & $142(72,4)$ \\
5yaş $\geq$ & $113(79,5)$ \\
5yaş< & $29(20,5)$ \\
Boyun-omuz & $6(3,1)$ \\
Üst ekstremite & $13(6,6)$ \\
Alt ekstremite & $11(5,6)$ \\
Gövde & $6(3,1)$ \\
Ayak-bilek & $2(1)$ \\
El-bilek & $10(5,1)$ \\
Diğer & $6(3,1)$ \\
TOPLAM & $196(100)$ \\
\hline
\end{tabular}

\begin{tabular}{|c|c|}
\hline Bulgu & n (\%) \\
\hline Zedelenme yok & $35(17,9)$ \\
\hline Yumuşak doku travması & $76(38,8)$ \\
\hline Kırık & $2(10,7)$ \\
\hline Çıkık & $1(0,5)$ \\
\hline Laserasyon-kesi & $36(18,4)$ \\
\hline \multicolumn{2}{|l|}{ Kafatravması } \\
\hline Saçlıderikesi & $11(5,6)$ \\
\hline Saçlıderişişlik & $13(6,6)$ \\
\hline Fraktür & $2(1)$ \\
\hline Kontüzyon & $1(0,5)$ \\
\hline TOPLAM & $196(100)$ \\
\hline
\end{tabular}

Tablo 4. Baş boyun bölgesi travması olan olguların düştükleri yerlere göre dağılımları

\begin{tabular}{lcc} 
Düşme yeri & $\mathbf{n}(\%)$ & $\begin{array}{c}\text { Baş-boyun bölgesi } \\
\text { travması n (\%) }\end{array}$ \\
\hline Kendi yüksekliği & $65(31,8)$ & $46(70,7)$ \\
Yatak & $26(12,7)$ & $19(73,6)$ \\
Ranza & $4(1,9)$ & $2(50)$ \\
Beşik & $9(4,4)$ & $5(55,5)$ \\
Sandalye/koltuk & $24(11,7)$ & $13(54)$ \\
Bisiklet & $6(2,9)$ & $1(16,6)$ \\
Balkon & $5(2,4)$ & $5(100)$ \\
Kaydıraktan düşme & $5(2,4)$ & $2(40)$ \\
Diğer & $60(29,4)$ & $3(5)$ \\
Toplam & $204(100)$ & $96(100)$ \\
\hline
\end{tabular}

Yapılan radyolojik değerlendirmeler incelendiğinde, 141 $(\% 67,1)$ olguya direkt grafi, $53(\% 25,2)$ hastaya kraniyal bilgisayarlı tomografi (BT) çekildiği görüldü. Ranzadan düşen (3 hasta) tüm hastalarda BT de kırık tespit edilmiştir (Tablo 5). Direkt grafi çekilen olguların $11(\% 7,8)^{\prime}$ inde ekstremite kırı̆̆ı tespit edildi. $90 \mathrm{~cm}$ üzerinden düşen 16 olgunun ise 12 (\%12)'sine direkt grafi çekilmiş sadece üç hastada kırık tespit edilmiştir. Kraniyal tomografi (BT) çekilen olguların 40 (\%75)'ın da baş boyun bölgesinde travma bulgusu mevcuttu. Üç hasta yüksek enerjili travma $(>90 \mathrm{~cm})$ olarak değerlendirilmiş ve BT çekilmişti. Olgularında sekizinde $(\% 15,1)$ kafa kemiklerinde fraktür, ikisinde subdural kanama tespit edilmişti.

\begin{tabular}{|c|c|c|c|}
\hline Düşme yeri & n (\%) & $\begin{array}{c}\text { Kafatası } \\
\text { kemiklerinde } \\
\text { kırık yok } \\
\text { n (\%) }\end{array}$ & $\begin{array}{c}\text { Kafatası } \\
\text { kemiklerinde } \\
\text { kırık var } \\
\text { n (\%) }\end{array}$ \\
\hline Kendi yüksekliği & $65(31,8)$ & $7(10,7)$ & $1(1,5)$ \\
\hline Yatak & $26(12,7)$ & $4(15,3)$ & $1(3,8)$ \\
\hline Ranza & $4(1,9)$ & $3(75)$ & $0(0)$ \\
\hline Beşik & $9(4,5)$ & $2(22)$ & $2(22)$ \\
\hline Sandalye/koltuk & $24(11,7)$ & $5(21)$ & $1(4,1)$ \\
\hline Bisiklet & $6(2,9)$ & $2(33)$ & $0(0)$ \\
\hline Balkon & $5(2,4)$ & $1(20)$ & $1(20)$ \\
\hline Kaydıraktan düşme & $5(2,4)$ & $1(20)$ & $0(0)$ \\
\hline Diğer & $60(29,4)$ & $20(33,3)$ & $1(1,6)$ \\
\hline Toplam & $204(100)$ & $45(100)$ & $7(100)$ \\
\hline
\end{tabular}

Yetmiş beş hasta $(\% 40,1)$ mevcut klinik durumu nedeniyle acil gözlem ünitesine izleme alınmıştı. Bu olguların 54 (\%72)'ü kafa travması olan olgulardı. Olguların 30 (\%16)'una baş ve yüz bölgesindeki kesi-laserayon nedeniyle sütür atılmıştı. Değerlendirilen tüm hastalar herhangibir mortalite ve morbidite olmadan muayene, tedavi ve/veya gözlem ardından taburcu edildi. Altmış beş (\%31) olgu acil serviste değerlendirildikten sonra hasta başka bölümlere konsülte edilmişti. Bu olguların $28(\% 43,1)^{\prime}$ i plastik cerrahi bölümüne konsülte edilmişti (Tablo 6).

\begin{tabular}{lc}
\hline \multicolumn{2}{l}{ Tablo 6. Olguların izlem, takip ve tedavisi } \\
\hline Tedavi şekli & $\mathbf{n}(\%)$ \\
\hline Tedavi verilmedi & $49(26,2)$ \\
Sargı-elastik bandaj & $10(5,3)$ \\
Ortopedik müdahale anestezili & $4(2,1)$ \\
Ortopedik müdahale anestezisiz & $16(7,6)$ \\
Dikiş atıldı & $30(14,3)$ \\
Doku yapıştıııI & $3(1,6)$ \\
İlem & $75(40,1)$ \\
TOPLAM & $187(100)$ \\
\hline
\end{tabular}


Ebeveynlerin sosyokültürel ve ekonomik durumları Tablo 7'de gösterilmiştir. Babalarının 10 (\%6,3)'u çalışmıyor, 62 (\%37,3)'si lise mezunuydu. Annelerinde 113 (\%28,5)'ü çalışmıyor, $56(\% 35,2)$ 'sı lise mezunuydu. Aylık gelir düzeyi $73(\% 43,2)$ 'ünde $1500 \mathrm{tl}$ nin üzerindeydi.

\begin{tabular}{lc}
\multicolumn{2}{l}{ Tablo 7. Ailelerin sosyodemografik özellikleri } \\
\hline Baba çalışma durumu & $158(100)$ \\
\hline Çalışıyor & $148(93,7)$ \\
Çalışmıyor & $10(6,3)$ \\
Anne çalışma durumu & $158(100)$ \\
Çalışıyor & $45(28,5)$ \\
Çalışmıyor & $113(71,5)$ \\
Baba eğitim düzeyi & $166(100)$ \\
İlkokul & $13(7,8)$ \\
Ortaokul & $19(11,4)$ \\
Lise & $62(37,3)$ \\
Lisans & $50(30,1)$ \\
Yüksek lisans & $22(13,3)$ \\
Anne eğitim düzeyi & $159(100)$ \\
Okur-yazar değil & $1(0,6)$ \\
İlkokul & $30(18,9)$ \\
Ortaokul & $17(10,7)$ \\
Lise & $56(35,2)$ \\
Lisans & $42(26,4)$ \\
Yüksek lisans & $13(8,2)$ \\
\hline
\end{tabular}

Tüm olgular adli olgu olarak değerlendirildi. Üç olguda $(\% 1,8)$ çocuk istismarı şüphesi mevcuttu.

\section{TARTIŞMA}

Her yıl 2,8 milyon çocuk düşmeye bağlı yaralanmalardan dolayı Çocuk Acil serviste tedavi edilmektedir ve bu başvuruların büyük kısmını 5 yaş altı çocuklar oluşturmaktadır (7). Acil servislere başvuran olguların değerlendirildiği bir çalışmada düşme nedeniyle getirilen olgu sayısının 7.946.000 olgu/yıl olduğu ve bu olgularında \% 14' ünün 5 yaş altı çocuklar olduğu saptanmıştır (8). Ancak bu verilerde yetersizdir, gelişmekte olan ülkelerde sadece hastaneye başvuran olgulara ait verilerdir. Ülkemizde de bu konu ile ilgili yapılan çalışmalar sınırlı sayıdadır. Ülkemizde çocukluk çağı düşmeleri ile ilgili yapılan geriye dönük bir çalışmada, yaşları 5 ay-13 yaş arasında değişen 161 olgu değerlendirilmiş olguların \%31,1'inin 2 yaş altında olduğu ve \%35,4' ün beşik, yatak gibi ev eşyalarından düştüğü saptanmıştır (9). Bir ay-17 yaş aralığındaki hastaları kapsayan çalışmamızda hastaların \%75 i 5 yaş altında olup, beşik, yatak ve sandalye gibi ev eşyalarından düşme ön sırada yer aldı.

Çocuk Acil Servislere başvuran çocuk travma olgularının büyük bir kısmı yüksekten düşme sonucunda oluşmaktadır. Yüksekten düşmeler tüm yaş grupları için önemli bir morbidite ve mortalite nedenidir. Gelişmiş ülkelerde bu başvuru oranları \%25-34 arasındadır (10).
Düşme nedeniyle Çocuk Acil Servisimize başvuran hastalarda yaptığımız prospektif çalışmada, hastaların çoğunluğu erkekti. Diğer çalışmalarda da düşme nedeniyle başvuran olguların çoğunluğu erkek olup, erkek çocukların daha hareketli olmaları nedeniyle daha çok yaralanmaya uğradığını doğrulamaktadır (11-14).

Çalışmamızda literatürlede uyumlu olarak düşmeler yaz aylarında daha sık (\%65) görülmüştür (15).

Maclnnes ve arkadaşlarının 7 yaşın altındaki çocukları değerlendirdikleri çalışmada da en sık travmanın ev içinde meydana geldiğini tespit etmişlerdir (16-19). Çalışmamızda da hastalarımızın büyük kısmı literatürle de uyumlu olarak ev içinde düşme nedeniyle başvurdu.

Düşme olgularında kafa travmaları daha sık görülmektedir. Kafa travmaları, çocuklarda en sık görülen ölümcül yaralanmalardır ve her yıl yaklaşık 435.000 acil servis ziyaretine neden olur. Yetişkinlerle karşılaştırıldığında, çocukların kraniyal kemiklerinin daha ince, baş-gövde oranının daha büyük olması, bağışıklık sisteminin olgunlaşmamış olması ve termoregülasyondaki farklılıklar kafa travmasına yatkın hale getirir (20-22). Bizim çalışmamızda da literatürle uyumlu olarak düşme sonrası en çok etkilenen vücut bölgesi baş-boyun bölgesidir. Yaş aralığına göre değerlendirdiğimizde de baş boyun bölgesi travması olan hastaların \%80 i literatürle de uyumlu olarak 5 yaşın altındaydı.

Kafa travması gözlenen olguların 12'sinde $(\% 8,2)$ saçlı deride şişlik, 11 'inde $(\% 7,5)$ saçlı deride kesi, ikisinde $(\% 1,3)$ fraktür, birinde $(\% 0,6)$ sefal hematom, birinde $(\% 0,6)$ kontüzyon vardı.

Kafa travmasıyla başvuran hastalarda travmatik beyin hasarı tanısında altın standart BT dir. Ancak çocuk yaş grubunda radyasyonun zararlı etkilerinden dolayı BT çekilecek hastaları bazı kurallara göre belirlemek gerekmektedir (23). Çalışmamızda 53 (\%25) hastaya BT çekilmiş olup sekizinde (\%15) kırık, ikisinde $(\% 3,7)$ kanama mevcuttu.

Yaş büyüdükçe çocuklarda baş çevresi vücudun gelişmesiyle birlikte küçülür, böylece ekstremite travması daha yaygın görülmeye başlar (24). Çalışmamızda diğer sık görülen travma ekstremite travmasıydı. Jalavandi ve arkadaşlarının yaptığı çalışmada her iki cinsiyette de üst ekstremite travması daha yaygın görülmüştür (25). Çalışmamızda da literatürle uyumlu olarak daha çok üst ekstremite travması görülmüştür $(26,27)$.

Çoğu hasta yumuşak doku travması tanısı aldı, kafa travması olan hastaların çoğunda kafa derisinde şişlik ve kesi mevcuttu.

Ev ortamında düşmelerin oluşması için risk faktörleri multifaktöryeldir. Çocuğun düştüğü yer birçok çalışmada farklılıklar göstermektedir (28). Bizim çalışmamızda daha çok kendi boyundan ve sırasıyla yatak, sandalye ve 
koltuktan düşmeler ön plandaydı. Başka bir çalışmada beşik ve yatak en çok iken bunu sırasıyla merdiven ve ardından pencere ve balkondan düşmeler takip etmiş (9).

Daha önce yapılan bir çalışmada ebeveynlerin sosyokültürel düzeyinin düşüklüğü ve anne yaşının 20'nin altında olması çocuklarda ölümlü yaralanmalarda büyük risk faktörü olarak bulunmuştur (29). Çalışmamızda anne baba eğitim düzeyi çoğunlukla lise ve üzerindeydi. Ancak annelerin büyük kısmı çalışmıyordu. Bu da yapılan diğer çalışmalarla da uyumlu olarak annelerin primer çocuk bakımıyla beraber ev işlerini de idame ettirirken çok yakın takip gereken 5 yaş altı çocukların bakımında aksama olmasıyla açıklanabilir (30).

Düşme nedeniyle Çocuk Acil Servise başvuran hastaların takip ve tedavisi diğer travma hastalarında olduğu gibi multi sistemik ve multidisipliner olmalıdır. Düşme nedeniyle Çocuk Acil Servise başvuran hastaların sayısı fazla olmakla birlikte hastaneye yatış oranı düşüktür. Çalışmamızda hastalarımızın \%40` gözlemde izlenirken, \%34 'üne girişim yapıldı.

Çalışmanın kısıtlılığı tek merkezde yürütülmüş olması, düşme yüksekliğinin ailenin söylemine göre göreceli hesaplanmasıdır.

\section{ETIK BEYANLAR}

Etik Kurul Onayı: Çalışma etik onay alındıktan sonra (Tarih 15.6.2009, Karar no:354), 01.06.2009 - 01.02.2010 tarihleri arasında Gazi Üniversitesi Tıp Fakültesi Çocuk Acil Servis'te ileriye dönük olarak yapılmıştır.

Aydınlatılmış Onam: Bu çalışmaya katılan hasta (lar)dan yazılı onam alınmıştır.

Hakem Değerlendirme Süreci: Harici çift kör hakem değerlendirmesi.

Çıkar Çatışması Durumu:Yazarlar bu çalışmada herhangi bir çıkara dayalı ilişki olmadığını beyan etmişlerdir.

Finansal Destek: Yazarlar bu çalışmada finansal destek almadıklarını beyan etmişlerdir.

Yazar Katkıları: Yazarların tümü; makalenin tasarımına, yürütülmesine, analizine katıldığını ve son sürümünü onayladıklarını beyan etmişlerdir.

\section{SONUÇ}

Düşme ilişkili travmalar sıklıkla ev içinde meydana gelmektedir. Ve en sık baş boyun bölgesi yaralanmaları görülmektedir. Özellikle okul öncesi dönemde yaşam ve oyun alanları evler olan çocukların sağlıklı şartlarda büyüyebilmesi ve düşme ilişkili travmalar nedeniyle acil servis başvurularının önlenmesinde ailelere çok iş düşmektedir. Güvenli ev ortamının nasıl oluşturulacağı ve alınacak önlemler hekimler tarafından ailelere anlatılmalıdır.

\section{KAYNAKLAR}

1. Zuckerbraun NS, Powell EC, Sheehan KM, et all. Community childhood injury surveillance: an emergency department-based model. Pediatr Emerg Care. 2004;20 (6):361-6.

2. Scuffham P, Chaplin S, Legood R. Incidence and costs of unintentional falls in older people in the United Kingdom. J Epidemiol Community Health. 2003;57:740-4.

3. Zagory JA, McLaughlin C, Mallicote M, et all. Retrospective Cohort Comparison of Fall Height in Children in the Greater Los Angeles Area: Targeting Populations for Injury Prevention.J Community Health. 2018;43 (5):986-92.

4. Laraque D, Barlow B, Durkin M. Prevention of youth injuries. J Natl Med Assoc. $1999 ; 91$ (10):557-71.

5. Chaudhary S, Figueroa J, Shaikh S, et al. Pediatric falls ages 0-4: understanding demographics, mechanisms, and injury severities. Inj Epidemiol. 2018:10;5 (Suppl 1):7.

6. Kuppermann N, Holmes JF, Dayan PS, et all. Pediatric Emergency Care Applied Research Network (PECARN). Identification of children at very low risk of clinically-important brain injuries after head trauma: a prospective cohort study. Lancet. $2009 ; 374: 1160-$ 70.

7. Simon TD, Bublitz C, Hambidge SJ. External causes of pediatric injury-related emergency department visits in the United States. Acad Emerg Med. 2004;11 (10):1042-8.

8. Mathers LJ, Weiss HB. Incidence and characteristics of fallrelated emergency department visits. Acad Emerg Med. 1998;5 (11):1064-70.

9. Güzel A, Karasalihoğlu S, Küçükuğurluoğlu Y. Evaluation of the fall-related trauma cases applied to our pediatric emergency department. Turkish Journal of Trauma \& Emergency Surgery 2007;13 (3):211-6

10. Kılıç S, Taşkınlar H, Bahadır G, et all.Analysis of pediatric trauma patients falling down from height. Mersin Univ Saglık Bilim Derg 2016; (9)3:131-7

11. Kocak S, Dundar ZD, Yavuz K, et al.Etiologic factors in falls from height in pediatric cases. Eur J Trauma Emerg Surg. 2012;38 (3):313-7.

12. Pressley JC, Barlow B. Child and adolescent injury as a result of falls from buildings and structures. Inj Prev 2005;11:267-733.

13. Babu A, Rattan A, Ranjan P, et al.Are falls more common than road traffic accidents in pediatric trauma? Experience from a Level 1 trauma centre in New Delhi, India.Chin J Traumatol. 2016;19 (2):75-8.

14. Maclnnes K, Stone DH. Stages of development and injury: An epidemiological survey of young children presenting to an emergency department. BMC Public Health. 2008;8:120.

15. Mack KA, Gilchrist J, Ballesteros MF. Injuries among infants treated in emergency departments in the United States, 20012004. Pediatrics. 2008;121 (5):930-7.

16. Mamdani MM, Upshur RE. Fall-related hospitalizations: what's in season? Can J Public Health. 2001;92 (2):113-6.

17. Razzak JA, Luby SP, Laflamme L. Injuries among children in Karachi, Pakistan — what, where and how. Public Health. 2004;118:11420

18. Mariam A., Sadik M., Gutema J. Patterns of accidents among children visiting Jimma University Hospital, Southwest of Ethiopia. Ethiop Med J. 2006;44:339-45.

19. Bangdiwala SI, Anzola-Perez E, Romer CC. The incidence of injuries in young people: I. Methodology and results of a collaborative study in Brazil, Chile, Cuba and Venezuela. Int J Epidemiol. 1990;19:115-24.

20. Alexiou Ga, Sfakianos G, Prodromou N. Pediatric head trauma. J emergencies, trauma Shock. 2011;4 (3):403-8.

21. Lam WH, Mackersie A. Paediatric head injury: incidence, aetiology and management. Paediatr Anaesth. 1999;9:377-85

22. Simon R, Gilyoma JM, Dass RM, et all. Paediatric injuries at Bugando Medical Centre in Northwestern Tanzania: A prospective review of 150 cases. J Trauma Manag Outcomes. 2013;7 (1):10 
23. Da Dalt L, Parri N, Amigoni A, et al. Italian guidelines on the assessment and management of pediatric head injury in the emergency department. Ital J Pediatr. 2018;44:7.

24. Kamboj $A$, Chounthirath $T$, Xiang $H$, et all. Traumatic brain injuries associated with consumer products at home among US children younger than 5 years of age. Clin Pediatr. 2017;56 (6):545-54.

25. Jalalvandi F, Arasteh P, Safari Faramani R, et all. Epidemiology of Pediatric Trauma and Its Patterns in Western Iran: A Hospital Based Experience..Glob J Health Sci. 2015; 26;8 (6):139-46.

26. Khosla S, Melton LJ , Dekutoski MB, et all. Incidence of childhood distal forearm fractures over 30 years: a population-based study. JAMA. 2003;17;290 (11):1479-85

27. Wang $\mathrm{H}, \mathrm{Yu} \mathrm{H}$, Zhou $\mathrm{Y}$, et al. Traumatic fractures as a result of falls in children and adolescents: A retrospective observational study.2017;96 (37):e7879.

28. Siddiqui $\mathrm{E}$, Ejaz K, Siddiqui U. Unintentional, paediatric domestic injury in a semi rural area of Karachi. J Pak Med Assoc. 2012;62 (7):638-43

29. Hong J, Lee B, Ha EH, et all. Parental socioeconomic status and unintentional injury deaths in early childhood: consideration of injury mechanisms, age at death, and gender. Accid Anal Prev. 2010;42 (1):313-9.

30. Brito MA, Melo AMN, Veras IC, et all. Risk factors in the domestic environment for falls in children under five years of age.Rev Gaucha Enferm. 2017;38 (3):e2017-1. 